\title{
Strategic Investment under Uncertainty: Merging Real Options with Game Theory
}

\author{
Kuno J.M. Huisman ${ }^{1}$, Peter M. Kort ${ }^{2,3}$, Grzegorz Pawlina ${ }^{4}$, \\ Jacco J.J. Thijssen ${ }^{5}$ \\ ${ }^{1}$ Centre for Quantitative Methods CQM B.V., P.O. Box 414, \\ 5600 AK Eindhoven, The Netherlands \\ ${ }^{2}$ Department of Econometrics \& Operations Research and CentER, \\ Tilburg University, P.O. Box 90153, 5000 LE Tilburg, The Netherlands \\ ${ }^{3}$ Department of Economics, University of Antwerp, Prinsstraat 13, \\ 2000 Antwerp 1, Belgium \\ ${ }^{4}$ Department of Accounting and Finance, Management School, \\ Lancaster University, LA1 4YX, United Kingdom \\ ${ }^{5}$ Department of Economics, Trinity College Dublin, Dublin 2, Ireland
}

January 6, 2004

\begin{abstract}
As becomes apparent from the standard text books in industrial organization (cf. Tirole, 1988, The Theory of Industrial Organization), the analysis of the effects of uncertainty within this field is yet underdeveloped. This paper shows that the new theory of strategic real options can be used to fill this gap. Based on the work by Smets (1991) standard models are identified, and they are analyzed by applying a method involving symmetric mixed strategies. As an illustration, extensions regarding asymmetry, technology adoption and decreasing uncertainty over time are reviewed. Among others, it is found that the value of a high cost firm can increase in its own cost. Furthermore, it is established to what extent investments are delayed when technological progress is anticipated, and it is found that competition can be bad for welfare.
\end{abstract}

\section{Introduction}

The main difference between financial options and real options is that in most cases real options are not exclusive. Exercising a given option by one party results in the termination of corresponding options held by other parties. For example, an option to open an outlet in an attractive location is alive only until a competitive firm opens its own store there.

However, as it is now the real option theory mainly considers single decision maker problems of firms operating in monopoly or perfect competition markets. But capital budgeting decisions can be strongly influenced by existing as well as potential competitors. The 
creation of the European Union and growing internationalization has increased interdependencies among firms in European industries. Former domestic market leaders now have to deal with competition. The conclusion is that there is a strong need to consider a situation where several firms have the option to invest in the same project. This new topic requires a merger between game theory and real options.

At present, only a few contributions deal with the effects of strategic interactions on the option value of waiting associated with investments under uncertainty (see Grenadier (2000) for a survey). One of the main reasons is that the application of game theory to continuous-time models is not well developed and often quite tricky. However, due to the importance of studying the topic of investment under uncertainty in an oligopolistic setting, it can be expected that more publications will appear in the immediate future.

This paper provides an overview of the state of the art, where we mainly concentrate on identical firms in a duopoly context. We begin by discussing two standard models. One model is a new market model (Dixit/Pindyck (1996)) and the other one considers a framework where the firms can enlarge an existing profit flow (Smets (1991)). Since firms are identical it seems natural to consider symmetric strategies. However, it can be expected that coordination problems arise in situations where investment is optimal only if the other firm refrains from doing so. While discussing the standard models we apply an approach which shows that imposing mixed strategies can deal with this coordination problem in an economically meaningful way. This approach, being inspired by the deterministic analysis in Fudenberg/Tirole (1985), was developed in Huisman (2001) (see also Huisman/Kort (2003)) and formalized in Thijssen/Huisman/Kort (2002). A similar attempt can be found in Boyer/Lasserre/Mariotti/Moreaux (2001). We show that joint investment can occur even if it is optimal for only one firm to invest. Furthermore, we discuss why it may be impossible to rule out such a joint investment even with pre-play communication. In other words, we argue that the outcome with both firms coordinating and investing sequentially with probability one, as in Smets (1991) and Dixit/Pindyck (1996), may be impossible to achieve.

One of our main results is the occurrence of rent equalization. According to this principle, the payoffs of the leader and of the follower are equal. This results from the fact that the leader has to invest no later than when the stochastic demand reaches the preemption point, i.e. the level at which the leader and the follower value functions intersect. Waiting longer would ultimately result in a preemptive investment of the competitor, attracted by the opportunity of realizing the leader's payoff. A direct implication of the rent equalization principle is that competition partly erodes the value of the option to wait.

Subsequently, we show that if the initial level of demand is higher than the preemption point, the only symmetric Nash equilibrium is the one which entails the firms playing mixed strategies. As a consequence, the firms may end up investing simultaneously when it is not optimal to do so, and even in negative NPV projects. This is a result of the coordination problem associated with the selection of the leader and the follower roles. Furthermore, we show that if firms already compete in the product market, they may avoid entering the preemption game and invest jointly when demand is sufficiently high. This results from the fact that foregoing a part of the future cash flow due to postponing the investment beyond 
the leader's optimal threshold can be more than compensated by a reduction in the present value of the investment cost (which will be incurred later).

As an illustration of the applicability of the strategic real option framework, we proceed by reviewing some of our own work. First, we show that introducing asymmetry in the investment cost function eliminates rent equalization present in the basic strategic real option model. Among other things, a surprising result is that the value of the high cost firm can increase in its own investment cost. In the second model, firms take into account the occurrence of future technologies when deciding about investment. A scenario is identified where the possibility of the arrival of a new technology results in a game with a second mover advantage. In such a case, it is optimal for a firm to be the follower and to wait for the most recent technology rather than to be the first mover locked into the inferior older technology. Finally, the third model extends the existing real option literature by studying a framework where over time information arrives in the form of signals. This information reduces uncertainty. In analyzing a new market model it is found that the mode of the game depends on the first mover advantage relative to the value of information free riding of the second mover, who observes the true state of the market after the leader's entry. Consequently, a firm has to trade off the benefit of entering the market earlier with the risk of incurring the investment cost in the bad state of the market.

The remainder of the paper is organized as follows. In Section 2 we present the basic models, while in Section 3 some recent literature is reviewed that makes use of this framework. Section 4 concludes.

\section{Standard Models}

The first paper dealing with a multiple decision maker model in a real option context is Smets (1991). It considers an international duopoly where both firms can increase their revenue stream by investing. Like in Fudenberg/Tirole (1985) two equilibria arise: a preemption equilibrium, where one of the firms invests early, and a simultaneous one, where both firms delay their investment considerably. A simplified version was discussed in Dixit/Pindyck (1996) in the sense that the firms are not active before the investment is undertaken. The resulting new market model only has the preemption equilibrium. In this section our symmetric mixed strategy approach is applied to both models. Section 2.1 treats the new market model (Dixit/Pindyck (1996), for a more thorough analysis see Thijssen/Huisman/Kort (2002)), and the Smets (1991)-model is discussed in Section 2.2 (see Huisman (2001) for a complete analysis).

\subsection{New Market Model}

This model considers an investment project with sunk costs $I>0$. After the investment is made the firm can produce one unit of output at any point in time. Since the number of firms is two, market supply is $Q \in\{0,1,2\}$. It is assumed that the firms are risk neutral, value maximizing, discount with constant rate $r$, and variable costs of production are absent. The market demand curve is subject to shocks that follow a geometric Brownian motion 
process. In particular, it is assumed that the unit output price is given by

$$
P_{t}=Y_{t} D(Q)
$$

in which

$$
\begin{gathered}
d Y_{t}=\mu Y_{t} d t+\sigma Y_{t} d \omega, \\
Y_{0}=y,
\end{gathered}
$$

where $y>0,0<\mu<r, \sigma>0$, and the $d \omega$ 's are independently and identically distributed according to a normal distribution with mean zero and variance $d t$. Furthermore, $D(Q)$ is a decreasing function, comprising the non-stochastic part of the inverse demand curve. ${ }^{1}$

Given the stochastic process $\left(Y_{t}\right)_{t \geq 0}$ we can define the payoff functions for the firms. If there is a firm that invests first while the other firm does not, the firm that moves first is called the leader. When it invests at time $t$ its discounted profit stream is given by $L\left(Y_{t}\right)$. The other firm is called the follower. When the leader invests at time $t$ the optimal investment strategy of the follower leads to a discounted profit stream $F\left(Y_{t}\right)$. If both firms invest simultaneously at time $t$, the discounted profit stream for both firms is given by $M\left(Y_{t}\right)$. Value functions $L\left(Y_{t}\right), F\left(Y_{t}\right)$, and $M\left(Y_{t}\right)$ are plotted in Figure 1 (for an analytical description of the value functions see Appendix A). In most cases, finding the optimal investment rule of a firm entails finding the value-maximizing threshold level of $Y_{t}$ at which the firm should exercise its real option. ${ }^{2}$

Let us first consider the optimal investment threshold of the follower, which we denote by $Y_{F}$. If the leader invests at $Y_{t}<Y_{F}$, the follower's value is maximized when the follower invests at $Y_{F}$. The follower's profit flow will be $Y D(2)$. Following familiar steps (cf. Dixit and Pindyck (1996)), we can find $Y_{F}$. It satisfies

$$
Y_{F}=\frac{\beta}{\beta-1} \frac{[r-\mu] I}{D(2)},
$$

where $\beta$ is given by

$$
\beta=\frac{\frac{1}{2} \sigma^{2}-\mu+\sqrt{\left[\frac{1}{2} \sigma^{2}-\mu\right]^{2}+2 \sigma^{2} r}}{\sigma^{2}}>1 .
$$

By rewriting (4) as

$$
\frac{Y_{F} D(2)}{r-\mu}=\xi I,
$$

where $\xi \equiv \beta /(\beta-1)$, we can observe that the optimal investment rule is a modified NPV formula with a mark-up $\xi$, which is larger than 1 . The mark-up $\xi$ reflects the impact of irreversibility and uncertainty (both not taken into account in the traditional NPV rule) and is increasing in uncertainty (it holds that $\partial \beta / \partial \sigma<0$ ).

\footnotetext{
${ }^{1}$ Equations (1) and (2) imply that the output price $P_{t}$ fluctuates randomly with a drift $\mu$ and standard deviation $\sigma$ and that it always takes positive values.

${ }^{2}$ In a strategic case, it often happens (as in the game considered in this section) that no pure strategy symmetric equilibria exist. In such a case the equilibrium strategy entails exercising the option at a given threshold with a probability strictly lower than 1 .
} 


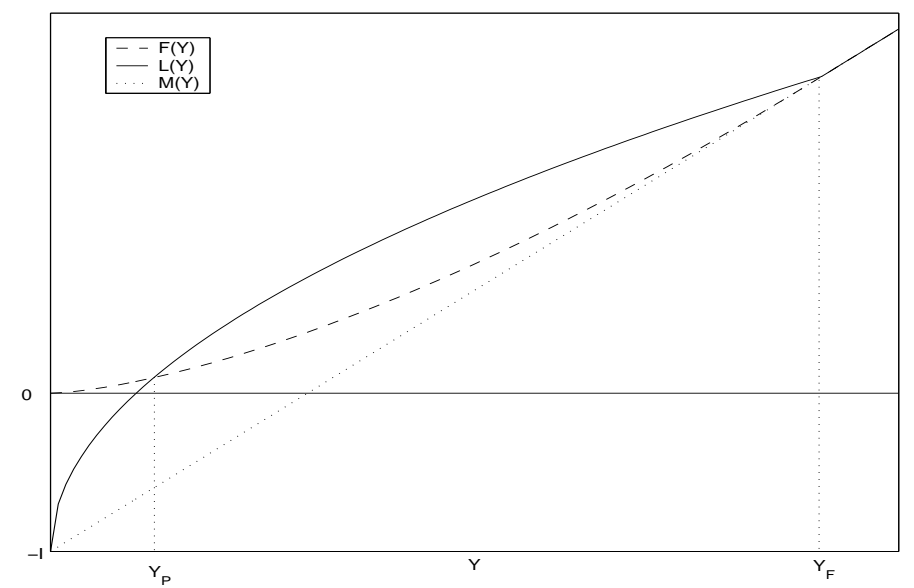

Figure 1: Value functions in the standard new market model.

Since firms are identical, there seems to be no reason why one of these firms should be given the leader role beforehand. The fact that firms are rational and identical also implies that it is hard to establish coordination on a non-symmetric equilibrium. Therefore, we concentrate on equilibria that are supported by symmetric strategies. We use the subgame perfect equilibrium concept for timing games as formalized in Thijssen/Huisman/Kort (2002). This approach extends the perfect equilibrium concept of Fudenberg/Tirole (1985) to stochastic games. (In the main text we present a less formal discussion of the firms' strategies. A formal description of the game is included in Appendix B.)

To describe the equilibrium, first define the preemption point

$$
Y_{P}=\min _{Y}\{Y \mid L(Y)=F(Y)\}
$$

see also Figure 1. This point is called preemption point because to the right of this point the leader value, $L\left(Y_{t}\right)$, exceeds the follower value, $F\left(Y_{t}\right)$, and this results in strategic behavior of the firms trying to preempt each other with investing as will become apparent from the description below. The equilibrium under consideration is therefore called a preemption equilibrium.

In Figure 1 three regions can be distinguished. The first region is defined by $Y_{t} \geq Y_{F}$. According to equation (B.4) the outcome exhibits immediate joint investment. Here the unit output price is large enough for both firms to enter the market.

In the second region it holds that $Y_{P} \leq Y_{t}<Y_{F}$. Immediate joint investment gives a payoff $M\left(Y_{t}\right)$. This is not a Nash equilibrium since if one of the firms deviates by waiting with investment until the process $Y$ hits the trigger $Y_{F}$, it obtains the follower value $F\left(Y_{t}\right)$. This follower value exceeds $M\left(Y_{t}\right)$ as long as $Y_{P} \leq Y_{t}<Y_{F}$, cf. Figure $1 .^{3}$

In case both firms refrain from investment and wait until $Y$ hits $Y_{F}$, they get the follower payoff $F\left(Y_{t}\right)$. Again this is not a Nash equilibrium, because if one of the firms deviates by investing this firm receives a payoff $L\left(Y_{t}\right)$ which is more than $F\left(Y_{t}\right)$ on this interval.

\footnotetext{
${ }^{3} \mathrm{As}$ it can be seen from Figure $1, M\left(Y_{t}\right)$ can be negative in interval $\left(Y_{P}, Y_{F}\right)$, in which case this is equivalent to the negative NPV of the joint investment.
} 
Since we restrict ourselves to symmetric strategies the only possibility left is to apply mixed strategies. Denote the probability that Firm $i$ invests at $Y_{t}$ by $\alpha_{i}(t)$. Consequently, $\alpha_{i}(t)$ can be interpreted as the probability that firm $i$ chooses row 1 in the matrix game

\begin{tabular}{c|c|c|}
\multicolumn{1}{c|}{ Invest } & Not invest \\
\cline { 2 - 3 } Invest & $\left(M\left(Y_{t}\right), M\left(Y_{t}\right)\right)$ & $\left(L\left(Y_{t}\right), F\left(Y_{t}\right)\right)$ \\
Not invest & $\left(F\left(Y_{t}\right), L\left(Y_{t}\right)\right)$ & repeat game \\
\cline { 2 - 3 } & & \\
\hline
\end{tabular}

The game is played at $Y_{t}$ if no firm has invested so far. ${ }^{4}$ Playing the game costs no time and if Firm $i$ chooses row 2 and Firm $j$ column 2 the game is repeated. If necessary the game will be repeated infinitely many times.

Since $\alpha_{i}$ and $\alpha_{j}$ are the probabilities that Firm $i$ and Firm $j$ invest at a given level of $Y_{t}$, they are the control variables that need to be optimally determined. To do so, define $V_{i}$ as the value of Firm $i$, which is given by

$$
\begin{aligned}
V_{i}= & \max _{\alpha_{i}}\left[\alpha_{i}\left[1-\alpha_{j}\right] L(Y)+\left[1-\alpha_{i}\right] \alpha_{j} F(Y)\right. \\
& \left.+\alpha_{i} \alpha_{j} M(Y)+\left[1-\alpha_{i}\right]\left[1-\alpha_{j}\right] V_{i}\right] .
\end{aligned}
$$

Since Firm $i$ invests with probability $\alpha_{i}$ and Firm $j$ with probability $\alpha_{j}$, the probability that Firm $i$ obtains the leader role, and thus receives $L(Y)$, is $\alpha_{i}\left[1-\alpha_{j}\right]$. Similarly, with probability $\left[1-\alpha_{i}\right] \alpha_{j}$ Firm $i$ is the follower, $\alpha_{i} \alpha_{j}$ is the joint investment probability, and with probability $\left[1-\alpha_{i}\right]\left[1-\alpha_{j}\right]$ nothing happens and the game is repeated. After writing down the first order conditions for Firm $i$ and Firm $j$, and imposing symmetric strategies, i.e. $\alpha_{i}=\alpha_{j}=\alpha$, it is obtained that

$$
\alpha=\frac{L(Y)-F(Y)}{L(Y)-M(Y)} .
$$

From Figure 1 we learn that $M\left(Y_{t}\right)<F\left(Y_{t}\right) \leq L\left(Y_{t}\right)$ on the relevant $Y_{t}$-interval $\left[Y_{P}, Y_{F}\right)$, so that we are sure that the probability $\alpha$ lies between zero and one. From (7) it is obtained that, given the difference $L\left(Y_{t}\right)-M\left(Y_{t}\right)$, the firm is more eager to invest when the difference between the payoffs associated with investing first and second is large.

After substitution of $\alpha=\alpha_{i}=\alpha_{j}$ into (6), the value of Firm $i$ can be expressed as

$$
V_{i}=\frac{\alpha[1-\alpha] L(Y)+[1-\alpha] \alpha F(Y)+\alpha^{2} M(Y)}{2 \alpha-\alpha^{2}}
$$

Of course, both firms do not want to invest at the same time, because it leaves them with the lowest possible payoff $M\left(Y_{t}\right)$. From (8) it can be obtained that the probability of occurrence of such a mistake is

$$
\frac{\alpha}{2-\alpha}
$$

${ }^{4}$ For $Y_{t}>Y_{P}$ this can happen either by mistake or if the game starts at $Y_{t}$. In all the other cases, at least one of the firms would have invested before (2) reached $Y_{t}$. 
which increases with $\alpha$. We also see that, whenever $\alpha$ is greater than zero, which is the case for $Y \in\left(Y_{P}, Y_{F}\right)$, the probability that the firms invest simultaneously is strictly positive. This is not in accordance with many contributions in the literature. For instance, Smets (1991, p. 12) and Dixit/Pindyck (1996), p. 313) state that "if both players move simultaneously, each of them becomes leader with probability one half and follower with probability one half".

Similarly, it can be obtained that the probability of a firm being the first investor equals

$$
\frac{1-\alpha}{2-\alpha}
$$

Due to symmetry this is also the probability of the firm ending up as the follower. Since the probability of simultaneous investment increases with $\alpha$, it follows that the probability of being the first investor decreases with $\alpha$, which is at first sight a strange result. But it is not that unexpected, because if one firm increases its probability to invest, the other firm does the same. This results in a higher probability of investing jointly, which leaves less room for the equal probabilities of being the first investor.

In the third region it holds that $Y_{t}<Y_{P}$. From Figure 1 it can be concluded that the follower value exceeds the leader value. Hence, investing first is not optimal so that both firms refrain from investing and wait until $Y_{t}=Y_{P}$. Then the second region is entered, and it can be obtained from (7) upon observing that $L\left(Y_{P}\right)=F\left(Y_{P}\right)$, that $\alpha=0$. From (10) we get that the probability for a firm to become leader is one half, and with the same probability this firm will be the second investor. Furthermore, from (9) it can be concluded that the probability of simultaneous investment at $Y_{P}$ is zero. All this implies that one of the firms will invest at $Y_{P}$ and the other one, being the follower, will wait with investment until $Y_{t}$ equals $Y_{F}$. Since the values of leader and follower are equal at $Y_{P}$, the firms have equal preferences of becoming the first or the second investor in this case. This is called rent equalization.

The first mover advantage results in equilibrium strategies in which both firms take a positive chance of making a mistake in order to get the leader payoff. Substitution of equation (7) in (8) shows that a firm sets its intensity $\alpha$ such that its expected value equals the follower value. Due to the risk-neutrality the firm is indifferent between obtaining the follower payoff for sure ( $\alpha$ equal to zero) and obtaining the follower payoff as expected value ( $\alpha$ as defined in (7)).

Let us now consider the following two numerical examples. Model parameters are assumed to be as follows: $r=0.05, \mu=0.015, \sigma=0.1, I=100, Y_{t}=8$, and $D(Q)=1-\frac{Q}{4}$. The optimal investment threshold of the follower, $Y_{F}$, equals 12.32. The value functions of the leader, the follower and with an immediate joint investment evaluated at $y=8$ are as follows (cf. (A.4), (A.3), and (A.5), respectively): $L(8)=39.05, F(8)=27.95$, and $M(8)=14.29$. Since $Y_{t}>Y_{P}=6.26$, firms' equilibrium strategies are of the mixed type with each firm attempting to immediately exercise its investment option with a positive probability. Using formula (7), we arrive at the equilibrium exercise probability $\alpha$ equal to 0.45 . Consequently, each firm becomes the leader (the follower) with probability $(1-\alpha) /(2-\alpha)=0.36$, whereas the probability of firms making a 'mistake' and investing jointly equals $\alpha /(2-\alpha)=0.28$. 
Our analysis is based on the assumption that the firms do not communicate in attempt to coordinate their actions. This results in a positive probability of a mistake, i.e. investing jointly when the level of demand is not sufficiently high. Such an outcome is ruled out by some authors, e.g. Smets (1991) and Dixit/Pindyck (1996), who assume that coordination is possible via 'tossing a coin'. Consequently, the game analyzed in these papers requires introducing a third player, the nature, who assigns the roles to the firms in the situation, where both of them want to invest immediately.

Essentially, in models that exclude joint investment, the game played in the region $\left(Y_{P}, Y_{F}\right)$ has the form:

\begin{tabular}{c|c|c|}
\multicolumn{1}{c|}{ Invest } & Not invest \\
\cline { 2 - 3 } Invest & $\left(\frac{1}{2}\left[L\left(Y_{t}\right)+F\left(Y_{t}\right)\right], \frac{1}{2}\left[L\left(Y_{t}\right)+F\left(Y_{t}\right)\right]\right)$ & $\left(L\left(Y_{t}\right), F\left(Y_{t}\right)\right)$ \\
\cline { 2 - 3 } Not invest & $\left(F\left(Y_{t}\right), L\left(Y_{t}\right)\right)$ & repeat game \\
\cline { 2 - 3 } & & \\
\hline
\end{tabular}

Since joint investment is excluded here by assumption, both firms attempt to optimally exercise their options with probability one and set $\alpha_{i}=\alpha_{j}=1$. Excluding the possibility of joint investment results on average in a later investment (one firm will always wait until $Y_{F}$ is reached). Moreover, not allowing for mixed strategies leads to higher valuations of firms. Under the endogenous selection mechanism, the value of each firm equals $F\left(Y_{t}\right)$ (cf. (8) combined with (7)), whereas in the setting of Smets (1991) and Dixit/Pindyck (1996) it is equal to $\frac{1}{2} L\left(Y_{t}\right)+\frac{1}{2} F\left(Y_{t}\right)>F\left(Y_{t}\right)$ for $Y_{t} \in\left(Y_{P}, Y_{F}\right)$. From this comparison it can be seen that making the appropriate assumptions concerning firms' available strategies is of utmost importance.

Such a coordination as in Smets (1991) and Dixit/Pindyck (1996) seems infeasible without introducing a third player (the nature) even when firms are allowed to communicate. Any collusive agreement among firms in region $\left(Y_{P}, Y_{F}\right)$ would be hard to sustain because of the following arguments. First, none of the firms would accept the follower's role, which is associated with a lower payoff than that of the opponent. Consequently, the only remaining possibility is the agreement on the firms' roles with a monetary transfer from the leader to the follower. However, even if we ignore the fact that such an act is illegal, the leader cannot credibly commit to meet his obligations once his investment is made. The follower, who anticipates the leader's default on its promised payment, enters the preemption game, which results in the mixed strategy equilibrium described above.

The outcome of Smets (1991) and Dixit and Pindyck (1996) is unlikely to occur even if successful coordination is allowed for (e.g. if some mechanism exists that enables credible commitment of the leader). Allowing for the possibility of pre-play agreement on the roles of the leader and of the follower, will neutralize the incentive to preempt (since preemption is not associated with the maximization of the firms' joint value). So, any binding agreement will not result in an equilibrium à la Smets (1991) or Dixit and Pindyck (1996). Instead, 
the leader will invest at some $Y$, say $Y_{L}$, which is greater than $Y_{P}$ but smaller than $Y_{F}$, such that $Y_{L}$ maximizes the leader value.

The choice between the endogenous selection mechanism resulting in mixed strategies and the 'tossing a coin' assumption depends on a particular application. Hoppe/LehmannGrube (2001) provides a justification of the latter in a context of computer fair: "If both firms plan to make an announcement at the same fair, one firm happens to have its press conference before the other with probability $1 / 2$. The other firm observes the announcement of the first firm, and may decide to postpone its introduction date to a later fair". However, if the fair venue allowed for parallel press conferences and the firms were scheduled for the same hour, applying the endogenous selection mechanism with mixed strategies and a positive probability of joint investment would be the only appropriate approach. Finally, Harsanyi (1973) shows that a mixed-strategy equilibrium of a complete information game, such as the one presented here, can be interpreted as the limit of a pure-strategy equilibrium of a slightly perturbed game of incomplete information. Therefore, instead of assuming that firms play mixed strategies, one can assume that the actual payoff resulting from becoming the leader equals $L\left(Y_{t}\right)+\varepsilon_{i}$, and $\varepsilon_{i}, i \in\{1,2\}$, has a density with a bounded support $[\underline{\varepsilon}, \bar{\varepsilon}]$, $\underline{\varepsilon}<0<\bar{\varepsilon}$. Firm $i$ knows $\varepsilon_{i}$ but does not observe $\varepsilon_{j}$. It can be shown that a symmetric Bayesian equilibrium in pure strategies exists. There is a critical value of $\varepsilon_{i}=\varepsilon_{j}=\varepsilon^{*}$ such that the optimal strategy for Firm $i$ is to invest if and only if $\varepsilon_{i}>\varepsilon^{*}$. As a consequence, firms can act optimally without resorting to mixed strategies (cf. Pawlina/Kort (2003)).

\subsection{Existing Market Model}

Contrary to the previous section, here two identical firms are already active in the market. They have the possibility of making an irreversible investment which results in a higher output price. A possible interpretation is that both firms have the possibility to adopt a new technology which after adoption increases the quality of the firm's product. Vertical differentiation leads to the situation where firms charge different prices for their products. Consequently, the resulting model is similar to the one of the previous section with the exception that expression (1) is replaced by

$$
P_{i t}=Y_{t} D_{N_{i} N_{j}}
$$

where, for $k \in\{i, j\}$ :

$$
N_{k}= \begin{cases}0 & \text { if firm } k \text { has not invested } \\ 1 & \text { if firm } k \text { has invested. }\end{cases}
$$

Keeping in mind that (i) the investment increases the unit output price for a given firm and (ii) the demand for the firm's product is higher if the competitor still produces the old quality products (thus not having invested yet), the following restrictions on $D_{N_{i} N_{j}}$ are implied:

$$
D_{10}>D_{11}>D_{00}>D_{01} \text {. }
$$

Further we assume that there is a first mover advantage to investment:

$$
D_{10}-D_{11}>D_{11}-D_{01}
$$


As expected, the resulting equilibria of this game also depend here on the payoffs of the leader $(L)$, the follower $(F)$ and immediate joint investment $(M)$, but, in addition to the analysis of the previous section, the equilibria also depend on the optimal joint investment payoff, which we denote by $J$ (see Appendix A for the definition). In the latter case the firms invest at a threshold level

$$
Y_{J}=\frac{\beta}{\beta-1} \frac{[r-\mu] I}{D_{11}-D_{00}} .
$$

When firms invest simultaneously they increase their profit flow from $Y D_{00}$ to $Y D_{11}$. For the follower it holds that investing changes the profit flow from $Y D_{01}$ to $Y D_{11}$. Consequently, the follower threshold is

$$
Y_{F}=\frac{\beta}{\beta-1} \frac{[r-\mu] I}{D_{11}-D_{01}} .
$$

Since $D_{01}<D_{00}$ (cf. (11)), before the investment takes place the follower's profits are lower than those of the simultaneous investors. Therefore, for the follower the incentive to invest is greater which explains why $Y_{F}<Y_{J}$.

It is important to note that if in the new market model the firms decide to invest simultaneously, their optimal threshold will be the same as the one of the follower. Thus it equals $Y_{F}$, as defined by (4). This is the case because for the follower as well as for simultaneous investment it holds that a profit flow of zero is replaced by a profit flow of $Y D(2)$. Consequently, in the new market model the follower payoff curve coincides with the payoff curve of optimal simultaneous investment, and for this reason the latter plays no role in the determination of the new market equilibrium.

If we again choose for symmetric strategies two cases can be distinguished in the existing market model. Depending on whether or not the optimal joint investment curve lies above the leader curve on the interval $\left[Y_{P}, Y_{F}\right)$, one of them will occur.

In the first case the leader curve lies above the optimal joint investment curve for some $Y \in\left[Y_{P}, Y_{F}\right)$, see Figure 2. Here the equilibrium strategy of Firm $i$ is also the strategy described in Section 2.1 .

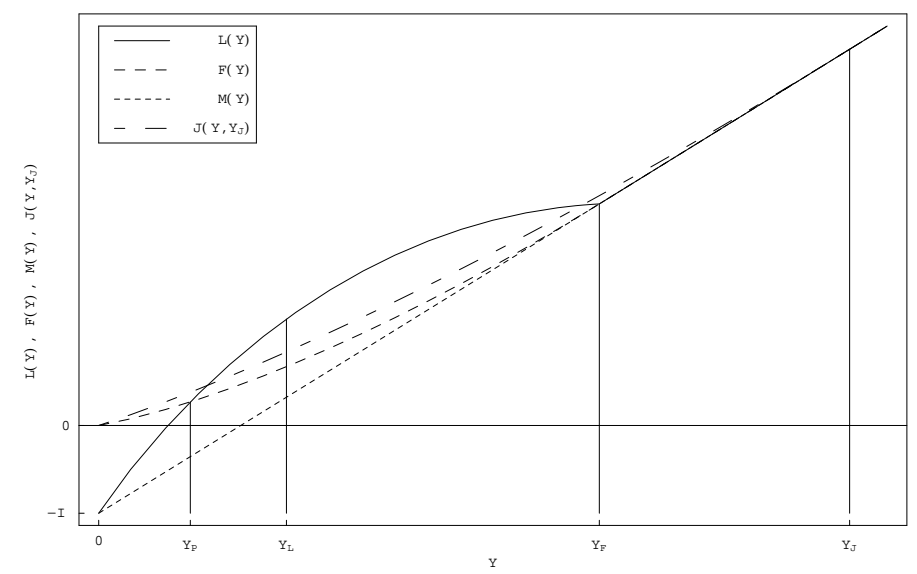

Figure 2: First Case: Preemption equilibrium in the standard existing market model. 
In the second case the optimal joint investment curve lies above the leader curve on the interval $\left[Y_{P}, Y_{F}\right)$, as can be seen in Figure 3. Besides the still existing preemption equilibrium, there exists a continuum of simultaneous investment equilibria from which simultaneous investment at $Y=Y_{J}$ Pareto dominates all other equilibria including the preemption equilibrium. In this Pareto dominant equilibrium the firms tacitly collude by refraining from investment until $Y_{t}$ becomes so large that it equals $Y_{J}$, which is beneficial to both of them. Therefore, in Boyer/Lasserre/Mariotti/Moreaux (2001) this equilibrium is called a tacit collusion equilibrium. Note that in Figure 2 this simultaneous equilibrium does not exist for $Y$ sufficiently small, since at the moment that $Y_{t}$ is such that $L\left(Y_{t}\right)>J\left(Y_{t}\right)$, Firm $i$ can gain by deviating in the form of investing immediately.

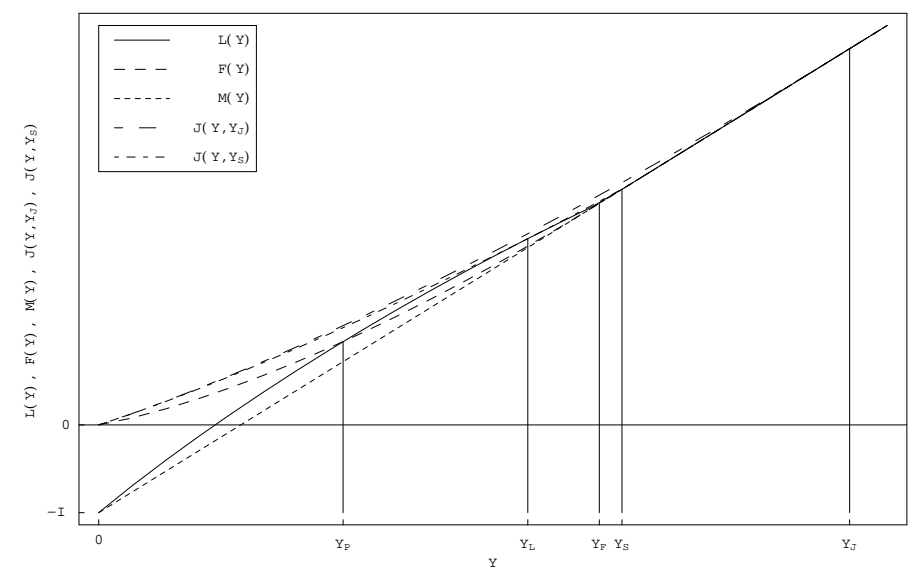

Figure 3: Second Case: Tacit collusion equilibrium in the standard existing market model.

Thijssen (2003) shows that the Pareto dominant equilibrium is also risk dominant, which makes selection of the Pareto dominant equilibrium more likely than selection of the preemption equilibrium.

Now the question remains under which scenario which case occurs. In Huisman (2001) it is proved that, no matter the degree of uncertainty, the equilibrium is always of the preemption type if $D_{10}$ is large enough, i.e. if the incentives to become leader are large enough.

The following example illustrates the case in which simultaneous investment equilibrium prevails. All the parameters are assumed to be as in the previous example (Section 2.1) with the difference that $D_{00}=0.25$ and $D_{01}=0.1$ (which reflects the existing market model assumption). In order to conclude which type of equilibrium will occur, we compare the value functions of the leader and with the optimal joint investment, both evaluated on the interval $\left(Y_{P}, Y_{F}\right)$. For the chosen set of parameter values, the value functions of the leader and with the joint investment are: $L\left(Y_{t}\right)=-100+21.43 Y_{t}-0.20\left(Y_{t}\right)^{2.32}$ and $J\left(Y_{t}\right)=7.14 Y_{t}+$ $0.05\left(Y_{t}\right)^{2.32}$. It holds that $L\left(Y_{t}\right)<J\left(Y_{t}\right)$ for all $Y_{t} \in\left(Y_{P}, Y_{F}\right)$. Consequently, the resulting equilibrium is of a simultaneous type. The optimal investment threshold corresponding to this equilibrium $\left(Y_{J}\right.$, cf. (12)) equals 24.63 . 


\section{Extensions}

This section treats three direct extensions to the standard models of Section 2. In Section 3.1 we incorporate some asymmetry in the sense that one of the firms can invest at a lower cost than the other one (see Pawlina/Kort (2001) for a more thorough analysis). Section 3.2 considers firm investment behavior in a scenario where with some probability a better technology will become available in the future. This technology adoption problem is analyzed in depth in Huisman/Kort (2000). Finally in Section 3.3, which summarizes Thijssen (2003, Part I), another type of uncertainty is considered, namely uncertainty that reduces because of information that becomes available over time.

\subsection{Asymmetric Firms}

The asymmetric model is a direct extension to the standard existing market model presented in Section 2.2 (see Huisman (2001) for incorporating asymmetry in a new market model). Also here we analyze the situation where two firms have an opportunity to invest in a profit enhancing investment project, but the difference is that they face different (effective) investment costs. Sources of potential costs asymmetry are, for instance, access to capital markets, organizational flexibility, and regulation.

For the model we can thus refer to Section 2.2 with the exception of the irreversible investment cost. We now have a low cost firm, say Firm 1, having investment cost $I$, and a high cost Firm 2 with investment cost $\kappa I$, where $\kappa \in[1, \infty)$.

Contrary to the model of Section 2.2, now there are three types of equilibria that can occur. The first type of equilibrium is the preemption equilibrium. It occurs in the situation in which both firms have an incentive to become the leader, i.e. when the cost disadvantage of Firm 2 is relatively small. Therefore, Firm 1 has to take into account the fact that Firm 2 will aim at preempting Firm 1 as soon as a certain threshold is reached (see also Section 2.1). This threshold, denoted by $Y_{21}^{P}$, is the lowest realization of the process $Y_{t}$ for which the leader and follower curve of Firm 2 are equal. As a consequence, when the initial value of $Y$ is sufficiently small, Firm 1 invests at

$$
\min \left\{Y_{21}^{P}, Y_{1}^{L}\right\},
$$

where $Y_{1}^{L}$ is Firm 1's optimal leader threshold equal to

$$
Y_{1}^{L}=\frac{\beta}{\beta-1} \frac{[r-\mu] I}{D_{10}-D_{00}} .
$$

Firm 2 invests at the follower threshold $Y_{2}^{F}$. The corresponding figure is qualitatively similar to Figure $2 .^{5}$

The second type of equilibrium is the sequential equilibrium. This one occurs when Firm 2 has no incentive to become the leader because of a significant cost disadvantage. In such a case, the follower curve of Firm 2 always lies above its leader curve. Then Firm 1 simply maximizes the value of the investment opportunity, which, provided that the initial level

\footnotetext{
${ }^{5}$ Of course, if the initial value of process $(2), y$, is higher than $Y_{21}^{P}$, the mixed strategy preemption equilibrium of Section 2.1 will occur.
} 


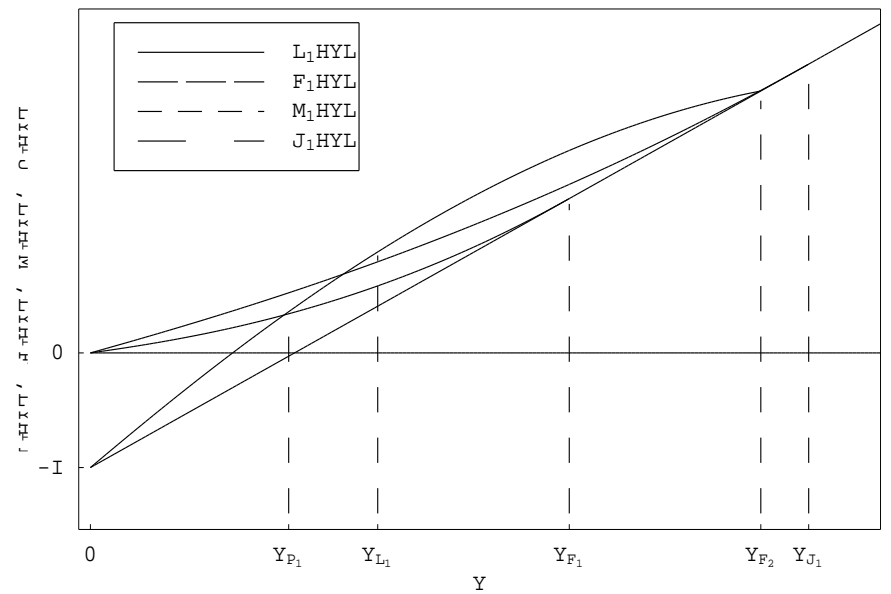

Figure 4: Firm 1's value functions when the resulting equilibrium is of the sequential type.

of $Y_{t}$ is sufficiently low, always leads to investment at the optimal threshold $Y_{1}^{L}$. In other words, Firm 1 acts as if it has exclusive rights to invest in a profit enhancing project. Of course, Firm 1's payoff is still affected by Firm 2's investment. As in the previous case, Firm 2 invests at its follower threshold $Y_{2}^{F}$. Figures 4 and 5 illustrate the firms' payoffs associated with the sequential investment equilibrium. The last type of equilibrium is the simultaneous equilibrium. The difference with the simultaneous equilibrium in Section 2.2 is that here the optimal joint investment thresholds differ for the firms. Since the optimal threshold of Firm 1 is lower than that of Firm 2, the firms will jointly invest at that threshold. ${ }^{6}$ The corresponding figures are qualitatively similar as Figure 3.

An important question is which equilibrium occurs when. It turns out that two critical values of cost asymmetry, $\kappa^{*}$ and $\kappa^{* *}$, exist that separate the equilibrium regions:

$$
\kappa^{*}=\left(\frac{u^{\beta}-1}{\beta(u-1)}\right)^{\frac{1}{\beta-1}} \text { and } \quad \kappa^{* *}=\max \left(w\left(\frac{\beta(v-1)}{v^{\beta}-1}\right)^{\frac{1}{\beta-1}}, 1\right)
$$

where

$$
u=\frac{D_{10}-D_{01}}{D_{11}-D_{01}}, \quad v=\frac{D_{10}-D_{00}}{D_{11}-D_{00}}, \quad \text { and } \quad w=\frac{D_{11}-D_{01}}{D_{11}-D_{00}} .
$$

It can be shown that firms invest simultaneously when the degree of asymmetry is smaller than the critical value $\kappa^{* *}$. From (14) it follows that the payoff of the first mover, $D_{10}$, has to be sufficiently low for $\kappa^{* *}$ being greater than 1 and the joint investment ever occurring. When $\kappa>\kappa^{* *}$, firms invest at distinct points in time. Here, $\kappa^{*}$ is the critical value separating the preemption and the sequential equilibrium regions. It holds that for $\kappa<(>) \kappa^{*}$ the resulting equilibrium is of a preemption (sequential) type. For parameter values such that $\kappa^{*}<\kappa^{* *}$, there is no level of asymmetry that supports the preemption equilibrium.

First mover advantage and uncertainty are the key factors driving the critical values $\kappa^{*}$ and $\kappa^{* *}$. An examination of (14) and (15) allows to observe that $\kappa^{*}$ increases and $\kappa^{* *}$

\footnotetext{
${ }^{6}$ It can be shown (see Pawlina/Kort (2001)) that $Y_{2}^{F}<Y_{1}^{J}$, so the optimal response to Firm 1 investing at $Y_{1}^{J}$ is to invest at $Y_{1}^{J}$ too.
} 


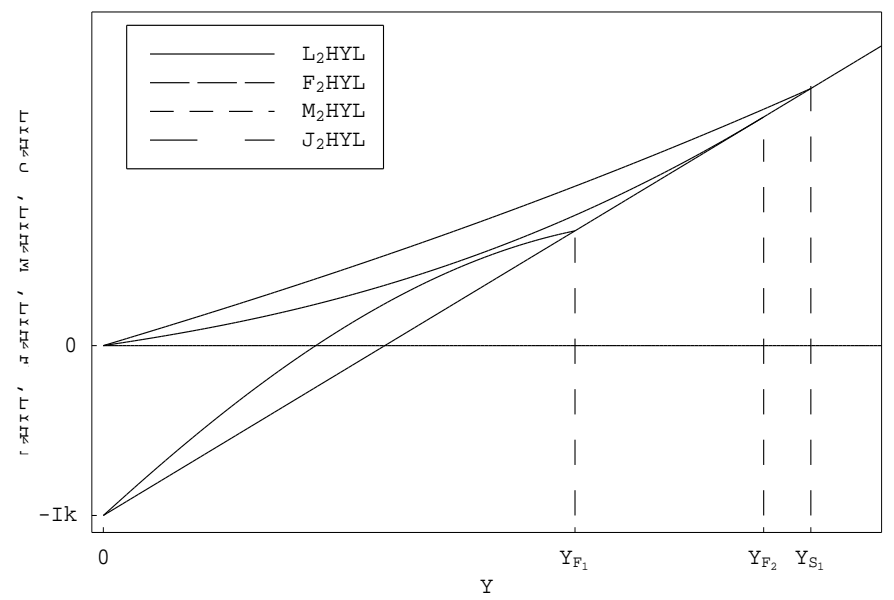

Figure 5: Firm 2's value functions when the resulting equilibrium is of the sequential type.

decreases with $D_{10}$. This means that the preemption region widens with a growing first mover advantage. The impact of uncertainty on the boundaries of equilibrium regions can by analyzed by looking at the sensitivity of the critical values $\kappa^{*}$ and $\kappa^{* *}$ to the changes in parameter $\beta$. It holds that $\kappa^{*}$ increases and $\kappa^{* *}$ decreases in $\beta$. Since $\partial \beta / \partial \sigma<0$, higher uncertainty results in a narrower range of model parameters supporting the preemption equilibrium. A smaller preemption region implies in turn a lower pace of investment and a higher valuation of both firms. ${ }^{7}$

A two-dimensional illustration of the above described relationships is depicted in Figure 6. When the investment cost asymmetry is relatively small and there is no significant first mover advantage, the firms invest jointly. When the first mover advantage becomes significant, Firm 1 prefers being the leader to investing simultaneously, which results in the preemption equilibrium. Finally, if the asymmetry between the firms is sufficiently high, the firms invest sequentially. An increase in uncertainty shifts curves $\kappa^{*}$ and $\kappa^{* *}$ to the right, therefore reducing the preemption region.

Interesting observations concerning the firms' valuations can be made if the firms' values are depicted as a function of the asymmetry parameter $\kappa$; see Figure 7 . Here the parameter values are chosen in such a way that for different values of the cost asymmetry parameter all three types of equilibria are possible.

One interesting observation is that in the region where the preemption equilibrium prevails, the value of Firm 2 is increasing in its own investment cost. This surprising result is caused by the fact that increasing $\kappa$ makes Firm 2 a 'weaker' competitor. This implies that the preemption threat of Firm 2 declines in the investment cost asymmetry, so that Firm 1 will invest later. This is beneficial for the cash flow of Firm 2 since, due to the fact that $D_{00}>D_{10}$, Firm 2 can enjoy a higher cash flow for a longer period. In this case the non-strategic, i.e. increasing investment cost for Firm 2, and strategic effects work in the

\footnotetext{
'Therefore, higher uncertainty boosts the firms' option values not only via a simple increase in the riskiness of underlying process but also via narrowing the region of a premature option exercise.
} 


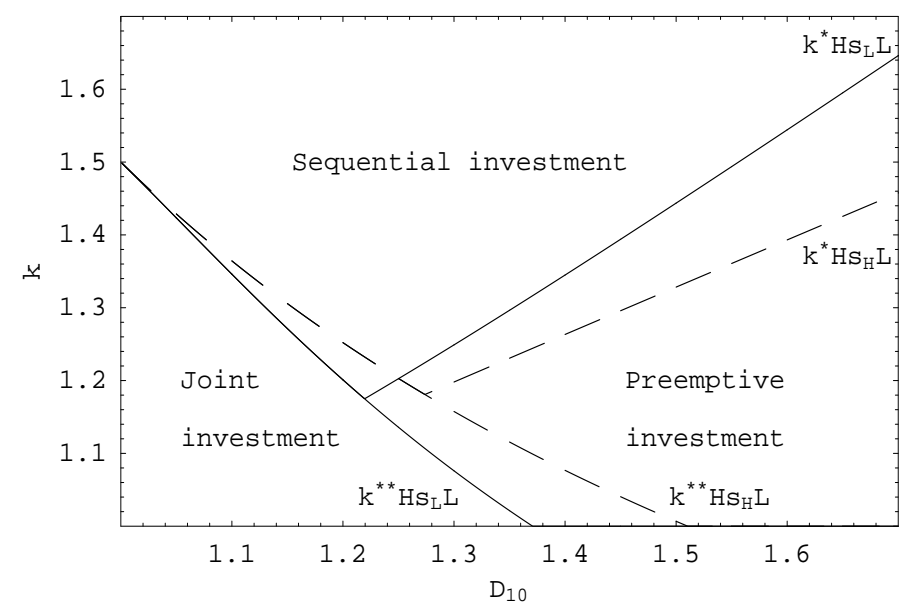

Figure 6: Regions of sequential, preemptive and joint investment equilibria for the set of parameter values: $r=0.05, \mu=-0.05, \sigma_{L}=0.1, \sigma_{H}=0.5, D_{00}=0.5, D_{01}=0.25$, and $D_{11}=1$.

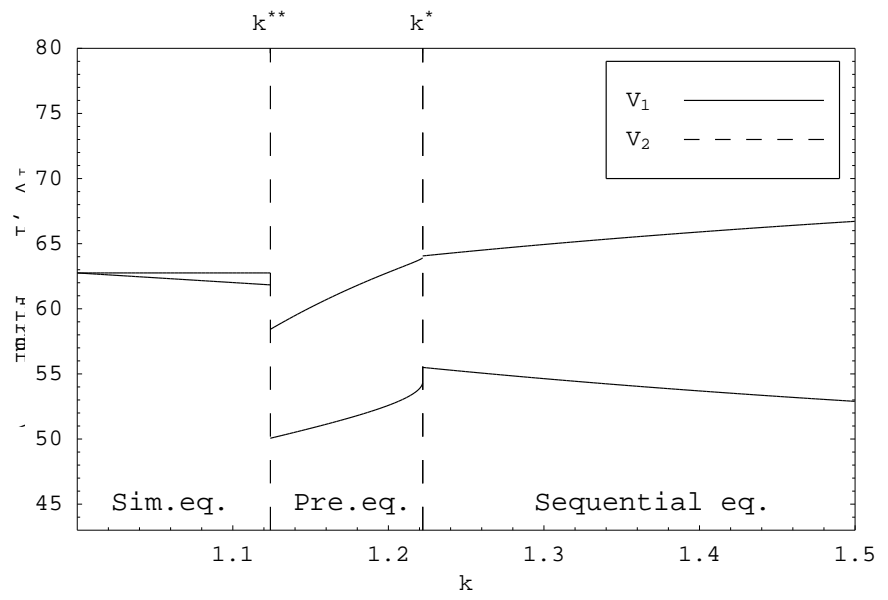

Figure 7: The value of Firm $i\left(V_{i}\right)$ corresponding to the regions of the sequential, preemptive and joint investment equilibria for the set of parameter values: $r=0.05, \mu=0.015, \sigma=0.1$, $D_{00}=0.5, D_{01}=0.25, D_{10}=1.33, D_{11}=1, I=100$, and $Y=4$. 
opposite direction and the latter effect dominates. ${ }^{8}$

Another observation is that at $\kappa^{* *}$ the value of Firm 1 jumps downward if the investment cost of the other firm is increased marginally. The reason is that this increase makes sequential investment for Firm 1 more attractive because of the increasing Firm 2's follower threshold. However, Firm 2 anticipates this and is willing to invest an instant before Firm 1 does. Again, Firm 1 reacts on this and this preemption mechanism leads to a, from the perspective of value maximization, too early investment of Firm 1 . This result can provide an explanation why firms engage in costly $R \& D$ races aiming at an early delivery of a new generation product when their competitive edge (here: a better access to a new market segment due to a lower investment cost) is diminishing. Here, a higher cost of Firm 2 results in Firm 1 switching from simultaneous investment regime to sequential one. Since in the latter the payoff of the leader exceeds the one of the follower, Firm 2 engages in a preemption game. As a result, both firms' value decreases (also of Firm 1, whose cost advantage is now higher!).

A decision to invest changes social welfare not only by influencing the valuation of firms but also by affecting consumer surplus (when investment leads to the launch of a new generation of products). Consequently, the impact of cost asymmetry on social welfare crucially depends on the relation between the magnitude of investment cost and the increase of consumer surplus attributable to investment. If the cost is relatively high and the firstmover advantage is small, social welfare is generally higher when $\kappa$ is close to 1 . This results from the fact that in the resulting tacit collusion equilibrium higher value of firms compensate the consumers' loss from a late delivery of a new product. In the opposite situation, i.e. when the investment cost is low, an increase of the consumer surplus resulting from the early investment in the preemptive equilibrium exceeds the loss of the firms' joint value associated with such an investment. Therefore, the preemptive equilibrium, which occurs when firms' costs sufficiently differ, is desirable. This observation allows for the conclusion that an equal access of competitors to a new technology may not be socially optimal, especially if the associated investment cost is high compared to the incremental consumer surplus resulting from investment.

\subsection{Technology Adoption with Progress}

The model extends the new market model of Section 2.1. At the beginning of the game, entering the market means producing with an existing technology 1 . However, the decision to invest in technology 1 will be influenced by technological progress. Adopting technology 1 would have been a bad decision if a little later a much better technology becomes available. In the model technological progress is included as follows. At the stochastic time $T$ a new

\footnotetext{
${ }^{8}$ For instance, one of the effects of the acquisition of Chrysler by Daimler-Benz in May 1998 was the latter firm's better access to the lucrative US market. Consequently, one of the reasons of Daimler's negative stock price reaction to the merger announcement was - according to our model - an increased likelihood of a fiercer competition against Ford and General Motors, the companies with already established a position in the US passenger car market. The takeover of Chrysler and a resulting reduction in the cost of expansion into the US market corresponds to the move to the left along the $V_{2}$ curve in the interior of segment $\left[\kappa^{* *}, \kappa^{*}\right]$. See also: Merger deal with Daimler values Chrysler at \$38bn, In: Financial Times, 7th May, 1998.
} 
and better technology 2 becomes available for the firms. Time $T$ is distributed according to an exponential distribution with mean $1 / \lambda$, so that the arrival of technology 2 follows a Poisson process with parameter $\lambda$.

It is assumed that firms can invest only once and that the investment costs of both technologies are equal to $I$. The price that Firm $i$ can charge at $t$ equals

$$
P_{i t}=Y_{t} D_{N_{i} N_{j}},
$$

where $N_{k}$ denotes the technology that firm $k(\in\{i, j\})$ is using. Hence, $N_{k} \in\{0,1,2\}$, where 0 means that the firm is not active. Higher technology can therefore be interpreted as resulting in a higher quality of a product. A difference in firms' prices reflects vertical product differentiation (cf. Section 2.2)

We make the following assumptions on the $D$ 's. First, a firm makes the highest amount of profits with a given technology if the other firm is not active (monopoly). It also holds that, given its own technology, profits are lowest when the other firm is a strong competitor, thus producing with technology 2. Second, given the technology of the competitor, the firm's profits are higher when it itself produces with technology 2 . In this way the following inequalities are obtained:

$$
\begin{array}{lll}
D_{20}> & D_{21}> & D_{22} \\
\vee & \vee & \vee \\
D_{10}> & D_{11}> & D_{12}
\end{array} .
$$

As can be expected, the outcome of the game heavily depends on the arrival rate of the new technology. If $\lambda \in\left[0, \lambda_{1}^{*}\right)$, with

$$
\lambda_{1}^{*}=\frac{[r-\mu] D_{11}}{D_{21}-D_{11}},
$$

then the probability of the arrival of a new technology is that low that the type of the resulting equilibrium is the same as in Section 2.1. Both firms are expected to invest in technology 1. But an increase of $\lambda$ leads to a higher threshold value. Therefore it can be concluded that the probability that both leader and follower will invest in technology 1 decreases with $\lambda$. This is the case since, if it happens that technology 2 arrives before (one of) the firms have invested, they (it) will invest in technology 2 instead.

The "Section 2.1 solution", but then with respect to investing in technology 2, also occurs if the arrival rate is large enough. This holds for $\lambda \in\left[\lambda_{3}^{*}, \infty\right)$, with

$$
\lambda_{3}^{*}=\frac{[r-\mu] D_{10}}{D_{22}-D_{12}} .
$$

Here the probability that the new technology will become available soon is that high that investing in the current technology is not considered. The firms wait for the arrival of the new technology after which the preemption game of Section 2.1 is played.

For $\lambda \in\left[\lambda_{1}^{*}, \lambda_{2}^{*}\right)$, with

$$
\lambda_{2}^{*}=\frac{[r-\mu] D_{10}}{D_{21}-D_{12}},
$$

the outcome is also a preemption equilibrium, but now the leader will invest in technology 1 and the follower in technology 2. As before the leader's adoption of technology 1 is 
conditional on technology 2 not arriving before the investment timing of the leader, and the probability that the leader will invest in technology 1 decreases with $\lambda$.

The only case left is when $\lambda \in\left[\lambda_{2}^{*}, \lambda_{3}^{*}\right)$. Also here the leader will invest in technology 1 and the follower in technology 2 , but the difference with the previous case is that now the arrival rate of the second technology is that high that the value of the follower is higher. The leader has the advantage of monopoly profits until the time that the follower invests in technology 2, but the disadvantage of producing with a less efficient technology after this date. Apparently here this disadvantage outweighs the monopoly profits.

A timing game with a higher payoff of the follower is called a war of attrition. In this particular case it can be shown that there does not exist a symmetric equilibrium. There are two asymmetric equilibria, where in each of them a different firm has the leader role. Here neither firm would like to be the first investor, but if they both keep on waiting, their payoff will be even less than the payoff of the one that decides immediately to invest first.

\subsection{Uncertainty Being Reduced over Time}

The real option literature mainly considers intrinsic uncertainty that will always exist regardless of the firm having invested or not. This is the kind of uncertainty we dealt with in the paper until now. However, there exists also another kind of uncertainty, which is uncertainty that reduces because of information that becomes available over time. A key feature of the latter kind of uncertainty is that the information is imperfect. For example, consider the introduction of a new communication technology by a telecom firm. There will always be uncertainty about the demand for the new service, depending on e.g. the business cycle, the unemployment rate and so on. On the other hand, there is uncertainty about the level of structural demand for the new service. Due to marketing research the firm gains more insight about structural demand, which decreases uncertainty. Since a marketing survey consists of a sample and not the entire population, the signals that it provides on the profitability of the investment are imperfect.

The model treated in this section deals with the kind of uncertainty that reduces over time due to the arrival of new information. Consider two identical firms that face the choice of investing in a certain project. The project can be either good (denoted by $H$ ), leading to high revenues, $U_{L}^{H}$ for the leader, $U_{F}^{H}<U_{L}^{H}$ for the follower or $U_{M}^{H} \in\left(U_{F}^{H}, U_{L}^{H}\right)$ in the case of simultaneous investment, or bad (denoted by $L$ ), leading to no revenue. As an example we can think of a duopoly game of quantity competition. Then in case the project is good the leader captures a Stackelberg advantage, and simultaneous investment implies a Cournot-Nash equilibrium. The sunk costs involved in investing in the project are given by $I$.

After investment has taken place by at least one firm the state of the project becomes immediately known to both firms. Hence, this creates a second mover advantage. If the firms do not invest simultaneously, the follower decides on investing immediately after the true state of the project is revealed.

When the firms receive the option to invest, they have a prior belief about the investment project being good or bad. The ex ante probability of high revenues is $p_{0}$. Occasionally the 


\begin{tabular}{c|c|c} 
& $h$ & $l$ \\
\hline$H$ & $\phi$ & $1-\phi$ \\
\hline$L$ & $1-\phi$ & $\phi$
\end{tabular}

Table 1: Probability of a signal indicating a good or bad project, given the true state of the project.

firms receive a signal indicating the project to be good (an $h$-signal) or bad (an $l$-signal). The probabilities with which these signals occur depend on the true state of the project. To model the imperfectness of signals, it is assumed that a correct signal always occurs with probability $1 / 2<\phi<1$, see Table 1 (note that the signal is uninformative if $\phi=1 / 2$ ). In this table the first row (column) lists the probabilities in case of a good project (good signal) and the second row (column) in case of a bad project (bad signal). The signals' arrivals are modelled via a Poisson process with parameter $\lambda$.

Both firms have an identical prior belief $p_{0} \in[0,1]$ in the project being good that is common knowledge. Let $g$ and $b$ be the number of $h$-signals and $l$-signals, respectively. Then it is shown in Thijssen/Huisman/Kort (2003) that

$$
p=p(g, b)=\frac{\phi^{g-b}}{\phi^{g-b}+\frac{1-p_{0}}{p_{0}}[1-\phi]^{g-b}} .
$$

At the moment of its investment, the leader's ex ante expected payoff equals

$$
L(p)=p\left[U_{L}^{H}-I\right]+[1-p][-I]=p U_{L}^{H}-I .
$$

The follower only invests in case of a good project. Therefore, if the leader invests when the belief in a good project equals $p$, the ex ante expected payoff for the follower equals

$$
F(p)=p\left[U_{F}^{H}-I\right] .
$$

In case of mutual investment at belief $p$, each firm has an ex ante expected payoff that equals

$$
M(p)=p U_{M}^{H}-I .
$$

Beforehand it is not clear whether this is a game of first mover or second mover advantages. If the Stackelberg advantage, i.e. $U_{L}^{H}-U_{F}^{H}$, is sufficiently large, the firms prefer to be the first investor and a preemption game results. On the other hand the follower is able to free ride on the investment decision taken by the leader since immediately after this investment all uncertainty is resolved. Then by refraining from investment the follower does not incur any losses in case the project turns out to be bad. If the value of this information spillover exceeds the Stackelberg advantage a war of attrition results. Thijssen (2003) finds that the game is a first mover game if

$$
\Psi<\frac{U_{L}^{H}-U_{F}^{H}}{U_{L}^{H}-I}
$$

where $\Psi$ is an increasing function of firms' discount rate, and a decreasing function of the informativeness parameter $\phi$ of the signal and of the Poisson arrival rate $\lambda$. If the inequality in (16) is reversed, the game is a second mover game. 
In case (16) holds the usual preemption game results. The analysis of this game is qualitatively similar to what we have seen in Section 2. On the other hand, when the game is a second mover game, firms eventually face the for these games usual dilemma that by investing immediately the leader value is obtained which is below the follower value, while waiting is bad for both firms if the other firm also waits. In this case a mixed strategy equilibrium exists where the investment probability is a function of the difference between the number of good and bad signals. During the time where this war of attrition goes on it happens with positive probability that both firms refrain from investment. It can then be the case that so many bad signals arrive that the belief in a good project becomes so low that the war of attrition is ended and that no firm invests for the time being. On the other hand, it can happen that so many positive signals in excess of bad signal arrive that at some time the Stackelberg advantage starts to exceed the value of the information spillover. This then implies that the war of attrition turns into a preemption game.

In Thijssen (2003) also some welfare results are reported. From the industrial organization literature it is known that a monopoly is bad for social welfare. Indeed, in the framework under consideration it is possible to find examples where a duopoly does better than a monopoly in terms of ex ante expected total surplus. However, within a duopoly it is also possible that in the case of a preemption equilibrium the first investor is tempted by the Stackelberg advantage to undertake the investment too soon from a social welfare perspective, i.e. when the environment is too risky. Moreover, there are two investing firms so that sunk costs are higher. As a result it happens that welfare is lower than in the monopoly case.

\section{Epilogue}

Besides our own extensions presented in Section 3, the framework being presented in Section 2 is used for many different applications. Grenadier (1996) applies it to the real estate market, Weeds (2002) and Miltersen/Schwartz (2002) study R\&D investments, Pennings (2002) and Pawlina/Kort (2002) analyze the product quality choice, Mason/Weeds (2002) study merger policy and entry, Boyer/Lasserre/Mariotti/Moreaux (2001) look at incremental indivisible capacity investments, Lambrecht (2001) takes into account debt financing, Nielsen (2002) and Mason/Weeds (2001) analyze the effects of positive externalities, Lambrecht/Perraudin (2003) consider incomplete information, Pawlina/Kort (2003) explicitly model demand uncertainty, while Sparla (2002) and Murto (2003) consider the decision to close down.

Application of our method to the standard models in Section 2 showed that mixed strategy equilibria can be handled in a very tractable fashion. Nevertheless, in the literature the prevailing method is to rule out simultaneous exercise beforehand (besides our own work, an exception is Boyer/Lasserre/Mariotti/Moreaux (2001)). This is either done by (i) assumption or by (ii) avoiding cases where suboptimal simultaneous investment can occur. Examples of (i) are, for instance, Grenadier (1996, pp. 1656-1657) who assumes that "if each tries to build first, one will randomly (i.e. through the toss of a coin) win the race", or 
Dutta/Lach/Rustichini (1995, p. 568) where it is assumed that "If both $i$ and $j$ attempt to enter at any period $t$, then only one of them succeeds in doing so" (for a similar argument, see Nielsen (2002)). Examples of (ii) are Weeds (2002) who in a new market model assumes that the initial value lies below the preemption point, so that sequential investment is the only equilibrium outcome (cf. Section 2), or Pennings (2002), Mason/Weeds (2002) and Pawlina/Kort (2002), where the leader and follower roles are exogenously assigned.

Overall, with this contribution we attempted to show that the strategic real option framework is a suitable tool to extend the industrial organization literature in a dynamic stochastic direction. By reviewing some existing research in this field, this paper proves that the interplay of game theory and real option valuation is a fascinating area that can generate economic results being significantly different from what is known from the existing industrial organization literature.

\section{Appendix}

\section{A Value Functions}

The value of Firm $i$ as the follower, $F_{i}\left(Y_{t}\right)$, equals

$$
\begin{aligned}
F_{i}\left(Y_{t}\right)= & E\left[\int_{t}^{T_{i}^{F}} Y_{s} D_{01} e^{-r(s-t)} d s\right] \\
& +E\left[e^{-r\left(T_{i}^{F}-t\right)}\left(\int_{T_{i}^{F}}^{\infty} Y_{s} D_{11} e^{-r\left(s-T_{i}^{F}\right)} d s-I_{i}\right)\right],
\end{aligned}
$$

in which

$$
T_{i}^{F}=\inf \left(t \mid Y_{t} \geq Y_{F, i}\right),
$$

where $Y_{F, i}$ is Firm $i$ 's follower investment threshold (cf. (4)). The first integral in (A.1) corresponds to the present value of profits obtained before the investment is undertaken. The second part of (A.1) reflects the present value of profits after the investment is made minus the associated sunk cost. For a new market model (Section 2.1) $D_{01}=0$. By applying the standard dynamic programming methodology (see, e.g., Dixit/Pindyck (1994) for a detailed discussion) the value of the follower can be expressed as:

$$
F_{i}\left(Y_{t}\right)=\left\{\begin{array}{cll}
\frac{Y_{t} D_{01}}{r-\mu}+\left(\frac{Y_{F, i}\left(D_{11}-D_{01}\right)}{r-\mu}-I_{i}\right)\left(\frac{Y_{t}}{Y_{F, i}}\right)^{\beta} & \text { if } & Y_{t} \leq Y_{F, i}, \\
\frac{Y_{t} D_{11}}{r-\mu}-I_{i} & \text { if } & Y_{t}>Y_{F, i} .
\end{array}\right.
$$

The first row in (A.3) is the present value of profits when the follower does not invest immediately. The first term is the payoff in case the follower refrains from investing forever, whereas the second term is the value of the option to invest. The second row corresponds to the present value of the profit stream resulting from immediate investment minus the investment cost. In Sections 2.1 and 2.2 the firms are symmetric and $Y_{F, i}=Y_{F, j}$. This equality does not hold in Section 3.1 .

Since for all the remaining cases the value of the firm has also a form of the present value of the cash flow stream under different market regimes minus the present value of 
the investment cost, we just restrict ourselves to presenting the final formulae. The value function of Firm $i$ as the leader can be expressed as

$$
L_{i}\left(Y_{t}\right)=\left\{\begin{array}{cll}
\frac{Y_{t} D_{10}}{r-\mu}-I_{i}-\frac{Y_{F, j}\left(D_{10}-D_{11}\right)}{r-\mu}\left(\frac{Y_{t}}{Y_{F, j}}\right)^{\beta} & \text { if } & Y_{t} \leq Y_{F, j}, \\
\frac{Y_{t} D_{11}}{r-\mu}-I_{i} & \text { if } & Y_{t}>Y_{F, j} .
\end{array}\right.
$$

The first row of (A.4) is the net present value of profits in case the follower does not invest immediately, taking into account the present value of future profits lost due to the follower's investment. The second row corresponds to the net present value of profits in a situation where it is optimal for the follower to invest immediately.

If the firms invest jointly, which is possible, for instance, when they play mixed strategies of Section 2.1, the value of Firm $i$ equals

$$
M_{i}\left(Y_{t}\right)=\frac{Y_{t} D_{11}}{r-\mu}-I_{i}
$$

Expression (A.5) is just equal to the net present value of perpetual cash flow stream in a situation where both firms are present in the market.

In a situation when firms invest simultaneously at the optimal threshold $Y_{J} \equiv \min \left\{Y_{J, i}\right.$, $\left.Y_{J, j}\right\}$ (cf. (12)), as in the tacit collusion equilibrium, the value function of Firm $i$ equals

$$
J_{i}\left(Y_{t}\right)=\left\{\begin{array}{cll}
\frac{Y_{t} D_{00}}{r-\mu}+\left(\frac{Y_{J}\left(D_{11}-D_{00}\right)}{r-\mu}-I_{i}\right)\left(\frac{Y_{t}}{Y_{J}}\right)^{\beta} & \text { if } & Y_{t} \leq Y_{J} \\
\frac{Y_{t} D_{11}}{r-\mu}-I_{i} & \text { if } & Y_{t}>Y_{J}
\end{array}\right.
$$

The first row of (A.6) consists of the present value of the firm based on the existing cash flow plus the option to increase instantaneous cash flow (from $Y D_{00}$ to $Y D_{11}$ ) at $Y_{J}$. The second row equals the net present value of perpetual cash flow stream when the simultaneous investment is made immediately.

\section{B Equilibrium Strategies}

In Thijssen/Huisman/Kort (2002) it is argued that in continuous time games a closed loop strategy of Firm $i$ consists of a collection of simple strategies $\left(G_{i}^{\tau}(t ; \omega), \alpha_{i}^{\tau}(t ; \omega)\right):[\tau, \infty) \times \Omega$ $\rightarrow[0,1] \times[0,1]$. For every path $\omega$ of $(2), G_{i}^{\tau}(t ; \omega)$ is the probability that Firm $i$ has invested by time $t$. Function $\alpha_{i}^{\tau}(t ; \omega)$ measures the intensity of atoms in the interval $[t, t+d t]$. It can be interpreted as the probability of playing the first row and the first column (for Firm $i$ and Firm $j$, respectively) in the $2 \times 2$ game depicted in Section 2.1. Playing this game takes no time and the game is repeated until at least one firm invests. For $\forall \omega \in \Omega$ it holds that:

(a) $G_{i}(t ; \omega)$ is non-decreasing and right-continuous with left limits,

(b) $\alpha_{i}^{\tau}(t ; \omega)$ is right differentiable and right-continuous with left limits,

(c) if $\alpha_{i}^{\tau}(t ; \omega)=0$ and $t=\inf \left\{s \mid \alpha_{i}^{\tau}(s ; \omega)>0\right\}$, then the right derivative of $\alpha_{i}^{\tau}(t ; \omega)$ is positive.

Property $(a)$ ensures that $G_{i}(\cdot)$ is a probability distribution. Properties $(b)$ and $(c)$ are for technical convenience and allow for calculating replacement probabilities and for endogenously determining firms' roles in the limiting case when $\alpha_{i}^{\tau}(t ; \omega)=0$. 
The strategy space for Firm $i$ is given by the set $S_{i}=\left\{\left(G_{i}(\cdot), \alpha_{i}^{\tau}(\cdot)\right) \mid G_{i}(\cdot)\right.$ satisfies $(a)$, and $\alpha_{i}^{\tau}(\cdot)$ satisfies $(b)$ and $\left.(c)\right\}$. The strategy space of the game is then $\mathcal{S}=S_{1} \times S_{2}$. To determine the firms' optimal policies the subgame perfect equilibrium concept is applied, while the firms' strategies are assumed to satisfy intertemporal consistency and $\alpha$-consistency conditions. ${ }^{9}$

First, the preemption equilibrium is considered. For $Y_{t} \in\left[Y_{P}, Y_{F}\right.$ ), the value of $\alpha_{i}$ (and, by symmetry, of $\alpha_{j}$ ) is determined by maximizing the value of the firm

$$
V_{i}=\max _{\alpha_{i}}\left[\alpha_{i}\left[1-\alpha_{j}\right] L(Y)+\left[1-\alpha_{i}\right] \alpha_{j} F(Y)+\alpha_{i} \alpha_{j} M(Y)+\left[1-\alpha_{i}\right]\left[1-\alpha_{j}\right] V_{i}\right] .
$$

Solving the first order condition and imposing symmetric strategies yields

$$
\alpha=\alpha_{i}=\alpha_{j}=\frac{L(Y)-F(Y)}{L(Y)-M(Y)} .
$$

Cases of $Y_{t}<Y_{P}$ and $Y_{t} \geq Y_{F}$ do not entail mixed strategies thus they are straightforward to solve. In the former, investment is never optimal $(\alpha=0)$, whereas in the latter a firm invests with probability $1(\alpha=1)$. This is also reflected in the corresponding values of the distribution function $G_{i}^{\tau}(t)$. The following equation summarizes the equilibrium strategies of Firm $i$ for all $Y_{t}$ (see Thijssen/Huisman/Kort (2002)):

$$
G_{i}^{\tau}(t)=\left\{\begin{array}{lll}
0 & \text { if } & Y_{t}<Y_{P} \\
\frac{L\left(Y_{t}\right)-M\left(Y_{t}\right)}{L\left(Y_{t}\right)-2 M\left(Y_{t}\right)+F\left(Y_{t}\right)} & \text { if } & Y_{P} \leq Y_{t}<Y_{F} \\
1 & \text { if } & Y_{t} \geq Y_{F}
\end{array}\right.
$$

and

$$
\alpha_{i}^{\tau}(t)=\left\{\begin{array}{lll}
0 & \text { if } & Y_{t}<Y_{P} \\
\frac{L\left(Y_{t}\right)-F\left(Y_{t}\right)}{L\left(Y_{t}\right)-M\left(Y_{t}\right)} & \text { if } & Y_{P} \leq Y_{t}<Y_{F} \\
1 & \text { if } & Y_{t} \geq Y_{F}
\end{array}\right.
$$

where the value of $G_{i}^{\tau}(t)$ for $Y_{P} \leq Y_{t}<Y_{F}$ is obtained by observing that it equals the probability of Firm $i$ either becoming the leader or investing jointly with Firm $j$. Since these probabilities are equal $(1-\alpha) /(2-\alpha)$ and $\alpha /(1-\alpha)$, respectively, using (B.2) and adding the probabilities yields the value of $G_{i}^{\tau}(t)$.

The tacit collusion equilibrium (Section 2.2) entails both firms investing with probability 1 at the Pareto dominant threshold $Y_{J}$. Therefore, the equilibrium strategy of Firm $i$ can be described as

$$
G_{i}^{\tau}(t)=\left\{\begin{array}{ll}
0 & \text { if } Y_{t}<Y_{J} \\
1 & \text { if } Y_{t} \geq Y_{J}
\end{array},\right.
$$

\footnotetext{
${ }^{9}$ Subgame perfect equilibrium requires that for $\forall \tau \in \mathbb{R}_{+}$a tuple of simple strategies $\left(G_{i}^{\tau}(t ; \omega), \alpha_{i}^{\tau}(t ; \omega)\right)$ be a Nash equilibrium for the subgame starting at $\tau$. Intertemporal consistency requires that $G_{i}^{\tau}(v ; \omega)=$ $G_{i}^{t}(v ; \omega)$ and $\alpha_{i}^{\tau}(v ; \omega)=\alpha_{i}^{t}(v ; \omega)$ for any $\tau, t$, and $v$ such that $0 \leq \tau \leq t \leq v<\infty$ and $v=\inf \{u \mid A(u)=$ $A(v)\}$. A strategy is $\alpha$-consistent when for $\alpha_{i}(t ; \omega) \neq \alpha_{i}\left(t_{-} ; \omega\right)$ the jump in the probability distribution $G_{i}(\cdot ; \omega)$ satisfies

$$
G_{i}(t ; \omega)-G_{i}\left(t_{-} ; \omega\right)=\left(1-G_{i}\left(t_{-} ; \omega\right)\right) \frac{\alpha_{i}(t ; \omega)}{\alpha_{i}(t ; \omega)+\alpha_{j}(t ; \omega)-\alpha_{i}(t ; \omega) \alpha_{j}(t ; \omega)},
$$

i.e. when it equals the probability of Firm $i$ replacing at $t$ (see also Fudenberg/Tirole (1985), p. 393, and Thijssen/Huisman/Kort (2002), p. 9).
} 
and

$$
\alpha_{i}^{\tau}(t)=\left\{\begin{array}{ll}
0 & \text { if } Y_{t}<Y_{J} \\
1 & \text { if } Y_{t} \geq Y_{J}
\end{array} .\right.
$$

Equations (B.5) and (B.6) imply that the cumulative probability of investment until hitting $Y_{J}$ is zero and one afterwards, and that the probability of exercising the investment option jumps to one at $Y_{J}$.

\section{References}

[1] Boyer, M., Lasserre, P., Mariotti, T., Moreaux, M. (2001): Real options, preemption, and the dynamics of industry investments. In: working paper, Universite du Quebec a Montreal, Montreal, Canada.

[2] Dixit, A.K., Pindyck, R.S. (1996): Investment under Uncertainty, 2nd printing, Princeton University Press, Princeton, USA.

[3] Dutta, P.K., Lach, S., Rustichini, A. (1995): Better late than early. In: Journal of Economics and Management Strategy 4, 563-589.

[4] Fudenberg, D., Tirole, J. (1985): Preemption and rent equalization in the adoption of new technology. In: The Review of Economic Studies 52, 383-401.

[5] Grenadier, S.R. (1996): The strategic exercise of options: development cascades and overbuilding in real estate markets. In: Journal of Finance 51, 1653-1679.

[6] Grenadier, S.R. (2000): Game Choices: The Intersection of Real Options and Game Theory, Risk Books, London, United Kingdom.

[7] Hoppe H., Lehmann-Grube U. (2001): Second-mover advantages in dynamic quality competition. In: Journal of Economics and Management Strategy 10 : 419-433.

[8] Huisman, K.J.M. (2001): Technology Investment: a Game Theoretic Real Option Approach, Kluwer, Dordrecht, The Netherlands.

[9] Huisman, K.J.M., Kort, P.M. (2000): Strategic technology adoption taking into account future technological improvements: a real options approach. In: CentER DP No. 200052, Tilburg University, Tilburg, The Netherlands.

[10] Huisman, K.J.M., Kort, P.M. (2003): Strategic investment in technological innovations. In: European Journal of Operational Research 144, 209-223.

[11] Lambrecht, B. (2001): The impact of debt financing on entry and exit in a duopoly. In: Review of Financial Studies 14, 765-804.

[12] Lambrecht, B., Perraudin, W. (2003): Real options and preemption under incomplete information. In: Journal of Economic Dynamics and Control 27, 619-643.

[13] Mason, R., Weeds, H. (2001): Irreversible investment with strategic interactions. In: CEPR Discussion Paper No. 3013. 
[14] Mason, R., Weeds, H. (2002): The failing firm defense: merger policy and entry. In: working paper, University of Southampton, Southampton, United Kingdom.

[15] Miltersen, K.R., Schwartz, E.S. (2002): R\&D investments with competitive interactions. In: working paper University of Southern Denmark, Odense, Denmark, and UCLA, Los Angeles, USA.

[16] Murto, P. (2003): Exit in duopoly under uncertainty. In: RAND Journal of Economics, forthcoming.

[17] Nielsen, M.J. (2002): Competition and irreversible investments. In: International Journal of Industrial Organization 20, 731-743.

[18] Pawlina, G., Kort, P.M. (2001): Real options in an asymmetric duopoly: who benefits from your competitive disadvantage?. In: CentER DP No. 2001-95, Tilburg University, Tilburg, The Netherlands.

[19] Pawlina, G., Kort, P.M. (2002): The strategic value of flexible quality choice: a real options analysis. In: working paper, Tilburg University, Tilburg, The Netherlands.

[20] Pawlina, G., Kort, P.M. (2003): Strategic capital budgeting: Asset replacement under market uncertainty. In: OR Spectrum 25, 443-479.

[21] Pennings, E. (2002): Optimal pricing and quality choice when investment in quality is irreversible. In: working paper, Bocconi University, Milano, Italy.

[22] Smets, F. (1991): Exporting versus FDI: The effect of uncertainty, irreversibilities and strategic interactions. In: working paper, Yale University, New Haven, USA.

[23] Sparla, T. (2002): Closure options in duopoly: the case of second mover advantages. In: working paper, University of Dortmund, Dortmund, Germany.

[24] Thijssen, J.J.J. (2003): Investment under Uncertainty, Market Evolution and Coalition Spillovers in a Game Theoretic Perspective, PhD-thesis Tilburg University, Tilburg, The Netherlands.

[25] Thijssen, J.J.J., Huisman, K.J.M., Kort, P.M. (2002): Symmetric equilibrium strategies in game theoretic real option models. In: CentER DP No. 2002-81, Tilburg University, Tilburg, The Netherlands.

[26] Thijssen, J.J.J., Huisman, K.J.M., Kort, P.M. (2003): The effect of information streams on capital budgeting decisions. Forthcoming in: European Journal of Operational Research.

[27] Weeds, H.F.(2002): Strategic delay in a real options model of R\&D competition. In: Review of Economic Studies 69, 729-747. 